\title{
Initial involvement into birding: triggers, gender, and decade effects-a mixed-methods study
}

\author{
Christoph Randler (iD ${ }^{1 凶} \&$ Nadja Marx ${ }^{1}$
}

Birdwatching is an increasing nature-related activity, with an important influence on data collection of citizen science programs. Initial involvement into a leisure activity is an important life event, but also of interest for nature conservation and citizen science projects. Here, we assessed the initiation into birding by an open-ended question. Based on an online survey, mainly in Austria, Germany and Switzerland we recruited 2668 participants, with 2464 people reporting a specific reason for their initial involvement. Data were analyzed by a combination of qualitative and quantitative methods. Initiation age was 22.90 years ( \pm 15.27$)$. The reasons for initial involvement were in descending order: social influence, nature experience, bird-centered triggers, education (formal/informal), cognitive-emotional aspects (interest, curiosity), other emotions, involvement via other hobbies/jobs, life-course events, ecological aspects, bird clubs/groups and opportunity. Men were more influenced by males and women more by females. Men experienced birding initiation more by club/group and the venue of other activities (job/hobby). Women were more influenced by nature experience, bird experience, emotions, and life-course events. Social initiation became less important during decades, while ecological aspect, education, other activities, and life-course events became more important. The study has implications on program developers and nature conservation organizations.

\footnotetext{
${ }^{1}$ Department of Biology, Eberhard Karls University, Tuebingen, Germany. ${ }^{凶}$ email: Christoph.randler@uni-tuebingen.de
} 


\section{Introduction}

nitial involvement or the initiation into a recreation or leisure activity, such as birdwatching, is an important life event, for the person himself or herself, but also from a nature conservation viewpoint. Concerning the viewpoint form nature conservation, citizen science projects have gained much attention during the last decades, especially when it comes to birding or birdwatching (Sullivan et al., 2014). Although citizen science projects are thriving, we still see a decline of species knowledge among school students and the public (Gerl et al., 2021; Randler and Heil, 2021). Concurrently to the decline of species, and species knowledge, there is also a decline of species specialists (Hopkins and Freckleton, 2002). Therefore, it is important to analyze in which ways people are recruited into a nature-related leisure activity such as birding and how the socialization occurs. These data can help to identify factors or reasons responsible for the initiation process because they, in turn, may give hints how to improve recruitment for citizen science data collection platforms, such as eBird (Sullivan et al., 2014). Further, concerning the decline of biodiversity, it would be helpful to know which venues can be used to increase biodiversity knowledge by drawing attention to a possible target audience. From the more general picture of leisure research, initiation into birding may represent an example of a nature-related activity, and the results from this study might be transferable to other animal-related or naturerelated activities. In addition to the general contribution with respect to a nature-related activity, birding is often related to data collection for citizen science projects (Sullivan et al., 2014). As initiation into birding usually happens before engagement within a citizen science activity takes place (Randler, 2021a, 2021b), it is an important prerequisite to study the basal initiation into this recreational activity. Therefore, birding can be an example for both, the initiation into a citizen science related leisure activity and the general picture of initiation into a nature-based activity.

\section{Literature review}

Birding and citizen science (CS). There are different typologies of CS projects (e.g., crowdsourcing, distributed-intelligence, community science, etc., see Ceccaroni et al., 2017). We here mostly focus on crowdsourcing or data collecting projects in birding. It is possible to study large-scale phenomena in nature with the help of CS projects. These projects, based on the data collection activity of volunteers, are important because the immense amount of data could not be collected with professional scientists (Bonney, 1991; Bonney et al., 2009). Data from such projects are important for biodiversity conservation, occurrence and abundance patterns, migration and monitoring of populations (McKinley et al., 2017). One of the best studied examples of successful CS is based in birdwatching or professional ornithology. Lay persons may contribute by easy observations, e.g., during watching a bird feeder, while highly skilled birders can help in monitoring breeding densities of many species, which requires a high knowledge (Bonney, 1991; Sullivan et al., 2014; Trumbull et al., 2000). For this reason, there are many CS projects in ornithology that target different populations of birdwatchers who differ in knowledge, specialization, and involvement levels (Bonter and Greig, 2021; Larson et al., 2020).

In this case, research into the initiation of birders can help identifying factors to increase participation in birdwatching and later for recruitment and participation in citizen science and in conservation projects. Many participants of CS projects have been recruited by accident, word-of-mouth or by internet campaigns, but retainment in CS projects is higher when participants are guided in-person (Parrish et al., 2019). When once "hooked" and people remain in CS projects (e.g., about bird data collection), they are on average higher skilled, more knowledgeable and the activity is more central to their lifestyle when compared with others that do not contribute to such ornithological CS platforms (Randler, 2021a, 2021b).

Birding and environmental issues. Apart from CS projects, birding may have an influence on the environment and the willingness to donate for nature projects. An analysis of the potential benefits and problems associated with birdwatching and ecotourism showed that birding improves the financial and environmental well-being of local communities and has a positive impact on biodiversity via the local community that starts to value bird diversity (Kutzner, 2019; Sekercioglu, 2002). Therefore, avitourism in a sustainable and responsible manner can be seen as a venue for conservation. Further, Cooper et al. (2015) showed that rural New York wildlife recreationists were four to five times more likely to engage in conservation behavior (donating, engaging in local conservation measures, etc.) than other recreationists. In addition, even within the group of birdwatchers in Alberta/Canada, heterogeneity existed with higher engaged and skilled birders donating a higher amount of money (McFarlane and Boxall, 1996). In Portugal, birdwatcher segments were identified who were willing to pay above average for conservation. These groups were named as "environmental stewards" and "birdwatching fans." However, these authors reported that the score obtained in an environmental questionnaire was not significantly related to their willingness to pay (Pintassilgo et al., 2021). Cheung et al. (2017), studying Chinese birdwatchers in Hong Kong, in contrast, reported a direct positive association between the birdwatchers' specialization and pro-environmental attitudes, suggesting that a higher knowledge about birds is positively related to environmental attitudes. Turning to birder behavior in the field, Australian birdwatchers reported to mitigate their influence on birds and to avoid disturbances (Weston et al., 2015). Thus, there is evidence that birding is related to environmental issues, e.g., responsible tourism, responsible behavior in the field, and higher developed environmental attitudes.

Children and wildlife. As most initiation processes happen during childhood and early adolescence, a closer look at the relationship between children and wildlife is necessary. Animals rank high in the view of Norwegian children and adolescents and animal-related activities like bird feeding, or watching hare, fox, and moose are common (Bjerke et al., 2001). Also, in secondary school teaching living animals during lessons are highly appreciated in Germany (Hummel and Randler, 2012). From a developmental viewpoint, German children are interested in animals, and their knowledge and interest increase from primary school (grade 1-4) to about grade 7, and afterwards knowledge decreases again (Randler, 2008; Randler and Wieland, 2010). This suggests that the age group of 9-12 years maybe an ideal time frame to catch interest into birds. Some intervention studies have been carried out to address this aspect: During a ten-week program, developed for feeder watching in the United States, in the group of seven- to nine-year old children, a gain in bird knowledge was found (Beck et al., 2001), and the increased knowledge was positively associated with parental education (Beck et al., 2001). Similarly, environmental attitudes and attitudes towards living organism could be improved by a 11-day teaching program in nature in 7th graders in Turkey (Genc et al., 2018). White et al. (2018) increased awareness for biodiversity and an increase in bird identification knowledge and attitudes by a special program exposing 7-10-year old UK children to their urban wildlife surroundings. Thus, programs to increase biodiversity awareness and 
knowledge usually start at this age. The study presented here is used to assess the initiation age and the initiation reasons to, in combination with the above-mentioned studies, draw conclusions on the ideal time frame and venue to start birding initiation.

Initiation into leisure. Exploration of how the leisure socialization process can be investigated requires answers to basic questions of when and with whom leisure is learned (Kelly, 1974). Studies concerning these questions revealed that activities started both, already during childhood, as well as in adult years (Kelly, 1974). Therefore, leisure socialization is a life-long process, but family influence was found in $63 \%$ of the studied persons (Kelly, $1974,1979)$. However, this may be dependent on the type of leisure activity. Further, life-course events have been often seen as having a negative influence on recreation specialization, i.e., highly skilled and qualified people reduced their activities because of life-course events, such as familial obligations (Kuentzel and Heberlein, 2008). In their research, Kuentzel and Heberlein (2008) defined different milestones of the family, including marriage, divorce, childbearing, and the empty nest. In a similar way, job-related changes were significant events, such as the first contract, a higher salary or retirement. Personality psychologist often invoke that a specific job or being recruited into the work force was a more important life-course event than familial events (Bleidorn et al., 2013). Thus, life-course events in general may have an influence in leisure and birding initiation.

Turning to social factors, or the more "infiltrative" process of socialization, support by family and peers may help a person to develop his or her birdwatching skills, because these persons may act as role model or mentor. In a parent-child study, parents regarded themselves as main transmitters of species knowledge to their 5-11 year old children (Remmele and Lindemann-Mathies, 2018), and a correlation between parents and children existed in knowledge scores about animals and plants (Remmele and Lindemann-Mathies, 2018). Comparable to other life-course changes, a trigger event (or epiphany) might be the releasing moment or factor to engage a person in birding, comparable to other trigger events, like becoming a vegetarian (Ploll et al., 2020). Thus, there might be a specific moment or experience that turns a person into a birder. Alternatively, as interest in birding can be a slow infiltration process or by socialization, it might occur also without a specific trigger event, e.g., by persistent influence of parents.

Birding initiation. Few studies examined initiation to birding (Canada: McFarlane 1996; USA: Moore et al., 2008). Most birders (60\%) started birding during their adult years (McFarlane, 1996). However, birders having started in childhood more often progressed into specialized birders (McFarlane, 1996), emphasizing the importance of early childhood initiation. McFarlane (1996) further classified factors into three groups: one was related to the family, another was concerned with knowledge/opportunity, and the third was labeled "leisure social world", including activities like field trips, companionship with others or taking bird-related courses. Initial involvement in birding was also studied by Moore et al. (2008), in this case, with a focus on gender differences. These authors compared means between men and women. These pioneering studies from McFarlane (1996) and Moore et al. (2008), however, used items with a Likert-type response format. Jones et al. (2017), also studying US Americans, used a qualitative approach (interviews) and reported that life-long science interest started during childhood and was influenced by events, resources, and family members. Compared to the quantitative, scale-based approaches of McFarlane (1996) and Moore et al. (2008), Jones et al. (2017) relied on a lower sample size.
The current study. This current study differs in some places from previous work. First, we followed a mixed-methods approach to portray birding initiation and to group these trigger events into different groups or categories. By using a bottom-up open-ended question, we received more diverse answers in comparison with a given number of questionnaire items that leave no space for personal expressions (comparable to the qualitative approach by Jones et al., 2017). By using qualitative content analysis, the participants can freely choose their own answers to the question. This turns out a much broader spectrum of possible initiation processes. Moreover, when looking at social aspects of the initiation process, we assess which gender influenced a given person, and finally, the reasons for initiation might differ between decades. This can be assessed because of the high sample size, that is much higher than any previous study in birding initiation.

Our study addresses the following questions:

1. What are the reasons for birding initiation?

2. Do reasons differ between men and women?

3. Are there differences in "social" initiation by genders?

4. Do reasons for birding initiation differ concerning decades?

\section{Methods}

Sample. We used an online research tool (SoSciSurvey) distributed among the German-speaking countries, mainly Austria, Germany and Switzerland. On the first page, the aims of the study were explained, and a formal consent was asked for. Participants were informed about data protection, anonymity, and their right to stop and retreat at any time during the process without any consequences. They had to actively click on "yes" to start the study. To a achieve a broad participation and to reflect the high diversity of birdwatchers, we recruited participants via many channels, e.g., using announcements on the webpages of large bird and nature-related organizations, like naturgucker.de, nabu.de, do-g.de, club300.de. Mailing lists were used from some organizations (Naturgucker.de). All regional chapters of scientific ornithological unions, societies and clubs were asked for participation by using postings on their websites or by distribution of the link on their mailing lists. In addition, Facebook groups with a relation to birdwatching were used to post an information about the study. Finally, an add was published in a printed birdwatching journal ("Vögel"). The aim was to depict the diversity and variation of birdwatchers of different organizations in Germanspeaking countries, from people preferring backyard birdwatching, to highly specialized birders and (semi-)professionals. The data that support the findings of this study are available on request from the corresponding author, $\mathrm{CR}$. The study was part of a larger questionnaire, consisting of additional variables, such as sleep behavior (Randler et al., 2021). Demographic variables were collected: current age, age at birding initiation, gender. For this analysis, we focused on a specific open-ended question: "Was there an experience or reason, why you have started with birdwatching?" (original in German: "Gibt es ein Ereignis oder einen Grund, warum Sie mit der Vogelbeobachtung begonnen haben?”).

Coding of the answers. The data were evaluated by means of the qualitative content analysis according to Mayring (2001, 2014, 2015, 2019): Mayring proposes a specific process model of the analysis. The analysis is segmented into individual interpretation steps, to ensure traceability, transferability and usability. A distinction is made between the inductive category formation, the explication and the structuring or deductive category formation. In the present work the inductive category formation was in the main focus, but was added with deductive parts (e.g., by use of a code book). As a first step, the categories were derived directly 
from the material in a generalization process. For example, when coding the person who was responsible for the initiation, we extracted the original word (e.g., "father", or "mother", "teacher" or "relatives"). In a next step, it could be joined to higher-order categories, like "family", "teachers", or "friends". In the end it is joined into the category "social". This happens in opposition for deductive category formation and without the inclusion of previous theoretical concepts (Mayring, 2015, p. 85). This has the advantage that the material can be depicted close to the object, without distortions and assumptions of the researchers (Mayring, 2015 , p. 86). That means, that the responses were used directly and not forced into a pre-existing category (in this case "social" from a deductive manner). This allows to find exploratively topics that may lead to new categories. To do this, the level of abstraction is set first. In this study, we first selected a very low level of abstraction and increased it towards the end of the analysis (see above, e.g., "father" on the first level). This creates a hierarchical structure comparable to a cluster analysis. Then the material is worked through line by line. If now the selection criterion occurs the first time, the first category will be formulated as a term or a short sentence taking into consideration the level of abstraction (Mayring, 2015, p. 87; e.g., in this case on the second level "family" and on the third level "social"). The next time the selection criterion is met, a decision must be made whether the criterion falls into the previous category (subsumption) or a new category must be formed. Having worked through a large part of the material, the material is being revised to verify that the aim of the analysis is still being pursued (Mayring, 2015, p. 87). In the present work this was now reverted to an actually deductive step which meant creating a category guide (code book) out of the previous analyses. Because of the large amount of material, this turned out to be advantageous. The category guide is composed of (Mayring, 2015, p. 97): 1. Definition of the categories: Definition of the text elements of a certain category. In addition, subcategories can be created if necessary. 2. Anchor examples: Concrete text passages that serve as an example for a category. 3. Coding rules: If there are problems with delimitation between individual categories coding rules established that serve for better assignment. Using this coding guide, the material has now been coded several times. If necessary, the guideline has been supplemented by new categories. This was repeated until no new categories could be created and thus all the material could be grasped using the coding book. For example, people mentioned that encountering a specific, often charismatic, bird species like a white stork (Ciconia ciconia) elicited their interest, but others reported a more generic level of bird taxonomy (e.g., waterbirds) or watching birds at a feeder (without any biological relevant taxonomy). At first, the different bird species were noted, but due to the diversity of species could not be grouped into categories (like, e.g., the white stork, the black stork, etc.) and were then coded as experience with specific birds, combining e.g., scientifically correct names with less precise answers. However, if we first would have set a subcategory "correct species name", then we would have coded into this category only responses were the species named by respondents could be assigned to a clear scientific name. All other information would have been lost (in this case, the mentioning of waterbirds, because it is not taxonomically identifiable). Following Mayring (2015), we found after coding several responses, that the initial category "correct species name" does not provide enough information, and then we went back to the data set and included also scientifically incorrect species names into a now newly defined category "specific experience with a bird". This captures the process better because it may be the encountering with a bird, irrespective whether it was a white stork or, e.g., a black stork. Finally, the level of abstraction was further increased to build main categories and subcategories.
In the example above, the main category was "bird experience". Table 1 gives an overview of the main categories with the associated subcategories. Unclear or difficult answers were discussed and refined between the authors until agreement was reached.

To structure the data, the data set was viewed several times. The coding book was repeatedly adapted and revised in this process. It crystallized 37 categories, which were grouped in twelve main categories with a total of 35 subcategories (two additional categories were "not codable" and "other"). Table 1 shows the percentage distribution of the individual main categories. Coding was generally done with $1=$ yes and $0=$ no. Every individual could contribute more than once to the data set. For example, when reporting "I have been always feeding birds with my grandpa.", we coded 1 for social (because of the grandpa), and 1 for bird feeding. For the social category, also gender of the person was coded, but only if it was clearly identifiable. Further, we categorized emotional aspects separately, and in addition, interest and curiosity were coded as a cognitiveemotional construct because both have cognitive and emotional components (please see for more discussion Gläser-Zikuda et al., 2005; Randler and Bogner, 2007).

Statistical analyses. As we had data on age and initiation age, we could retrospectively calculate the decade when participants started with birding. These were summarized into 10 -year bins, starting with pre-1960ies, 1961-1970 until 2020. We used crosstabs to check for differences between genders based on Fisher's exact test, and Kendall tau correlation to assess whether differences between initiation decades follow a trend pattern (increase or decrease). Means were compared by independent t-tests. Statistical analyses were carried out with SPSS 26.

\section{Results}

From the 2668 participants, $n=204$ explicitly stated that there was no specific reason for birding initiation. The following analyses are based on $n=2464$ people. Participants were on average (mean \pm SD) $46.98 \pm 16.12$ years old, started birding at the age of 22.90 years $( \pm 15.27$; Fig. 1$)$, and thus, had $24.06( \pm 19.33)$ years of birding experience. $N=1213$ were male, 1240 female, 11 nonbinary. 2300 were from Germany, 62 from Austria, and 99 from Switzerland; 3 were from other countries (Luxembourg, Liechtenstein, Italy). The initiation age (Fig. 1) shows that the initiation occurs most often in childhood and adolescence but can also happen any time in later life (Fig. 1).

Social influences are the most common reasons for birding initiation (Table 1), followed by nature experience. This includes specific traveling, or field trips. On third rank there is a birdcentered trigger, such as encountering a given species, experience with feeding birds or the fascination of bird flight, bird song and appearance. Formal education (school/university) also had an important impact on initiation. Further aspects are more in the emotional domain, with cognitive-emotional constructs, such as curiosity and interest placed on the fifth rank. Other emotions followed. Initial involvement also took place via other hobbies or jobs, e.g., when participants worked in civil services (e.g., for a nature conservation organization) and then started more serious birding. Also, some respondents were primarily nature photographers and then discovered the diversity of birds. Life-course events had an influence on initial involvement, with both positive (childbirth, acquire/rent a garden) and negative events (death of a partner, divorce). Ecological aspects (species declines) were less relevant, as were bird clubs or groups. Opportunity is on the last rank. Opportunity means that birdwatching grew out of an easy access to a natural area (locally) or as a by-product of other leisure activity. 
Table 1 Main categories (in bold) and subcategories for initial involvement into birding.

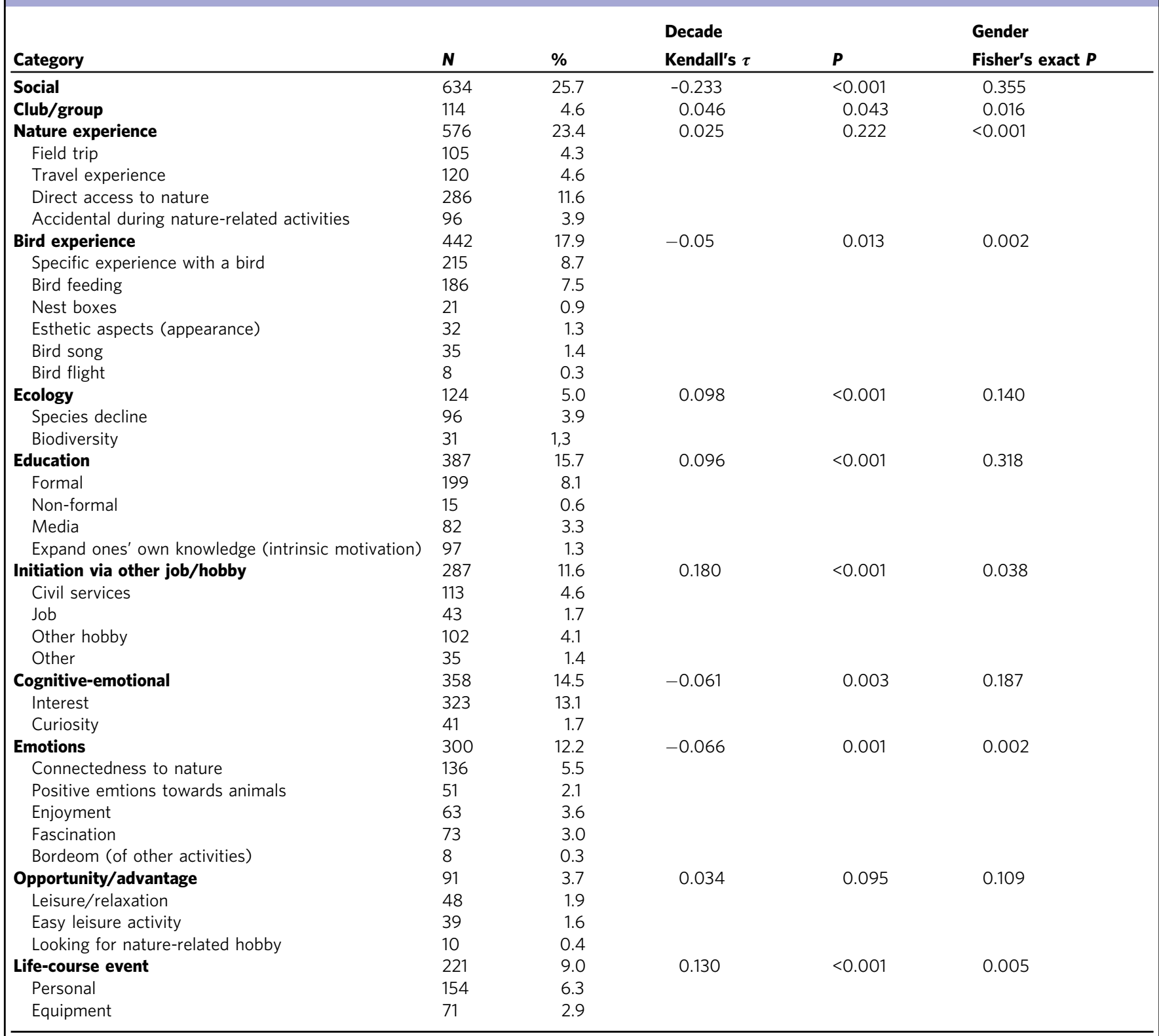

Decade effects were assessed with Kendall's $\tau$ (df always 6 ) and differences between men and women with Fisher's exact test. Categories "not codable" and "others" not presented in the Table. Every individual could contribute more than once to the data set (when different reasons have been reported), thus sums may exceed 100 percent.

Social initiation was the most important factor/category; therefore, we looked at it in more detail (Table 2). Family members and birding friends were the most important influencers, but also docents/teachers played a role. There were significant differences between men and women in the person who was responsible for their initiation. Men were more influenced by males and women more by females $\left(\chi^{2}=6.023, p=0.021\right.$, $n=297$; with continuity correction; Fig. 2).

Gender differences existed in the categories club/group, nature experience, bird experience, other activities (job/hobby), emotions, and life-course event (Table 1). Men experienced birding initiation more by club/group and the venue other activities (job/ hobby). Women were more influenced by nature experience, bird experience, emotions and life-course events. Further, we found strong decade effects (Table 1). However, owed to the high sample size, even small correlations become significant. Concerning the highest coefficients, social initiation became less important during decades, while ecological aspect, education, other activities, and life-course events became more important (see Figs. 3-5).

\section{Discussion}

Reasons for initial involvement. Our data showed that in most cases some kind of initiation or initial involvement took place. The most numerous categories were social factors, nature experiences, bird experiences and education. The social factors were also stressed by Kelly (1977), where over $60 \%$ of leisure activities in general started within a family context at childhood, while school played a minor role (Kelly 1977). Concerning birdwatching, Jones et al. (2017) reported a similar rate of about $50 \%$ of adult American citizen scientists who were inspired through family involvement. However, this is in a stark contrast to Moore et al. (2008) who studied adult Americans and where 


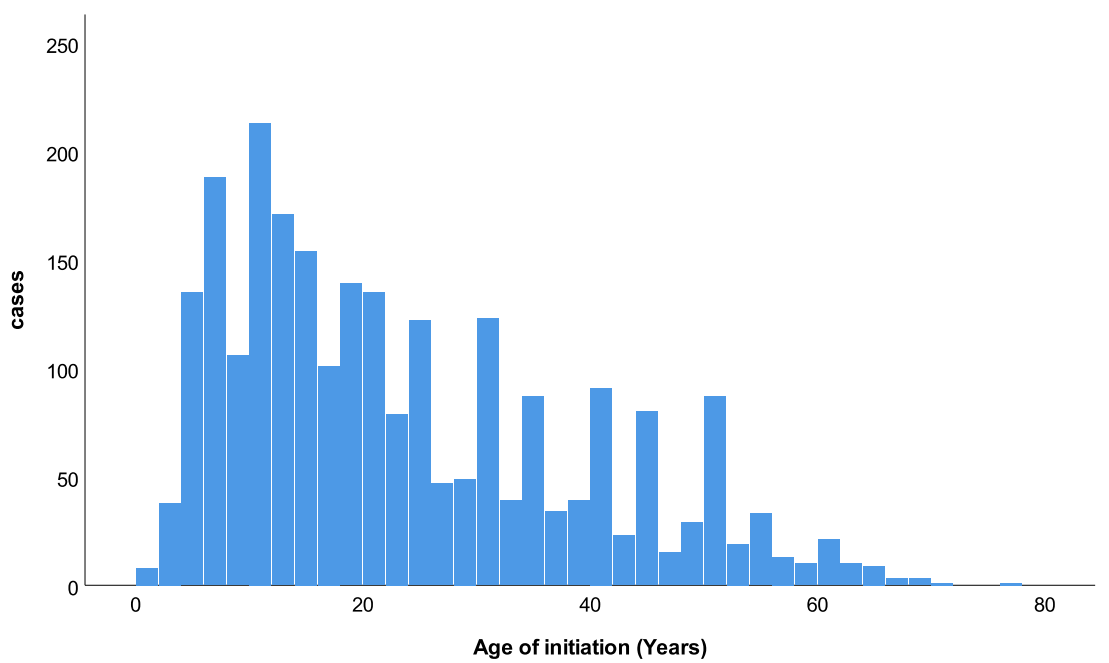

Fig. 1 Initiation age into birding. Mean age of the initiation into birding, number of cases according to age.

Table 2 Initial involvement by a person ranked by importance (except category other, placed at the end).

\begin{tabular}{llc} 
Person & N & percentage \\
\hline Father & 140 & 22.1 \\
Parents & 82 & 12.9 \\
Other family & 79 & 12.5 \\
Friend (birding friend) & 77 & 12.1 \\
Grandfather & 56 & 8.8 \\
Teacher/docent & 41 & 6.5 \\
Spouse/Partner & 32 & 5.0 \\
Mother & 24 & 3.8 \\
Expert (like field trip leader) & 21 & 3.3 \\
Work place & 20 & 3.2 \\
Grandmother & 11 & 1.7 \\
Child(ren) & 10 & 1.6 \\
Grandparents & 9 & 1.4 \\
Others & 32 & 5.0 \\
Total & 634 & 100 \\
\hline
\end{tabular}

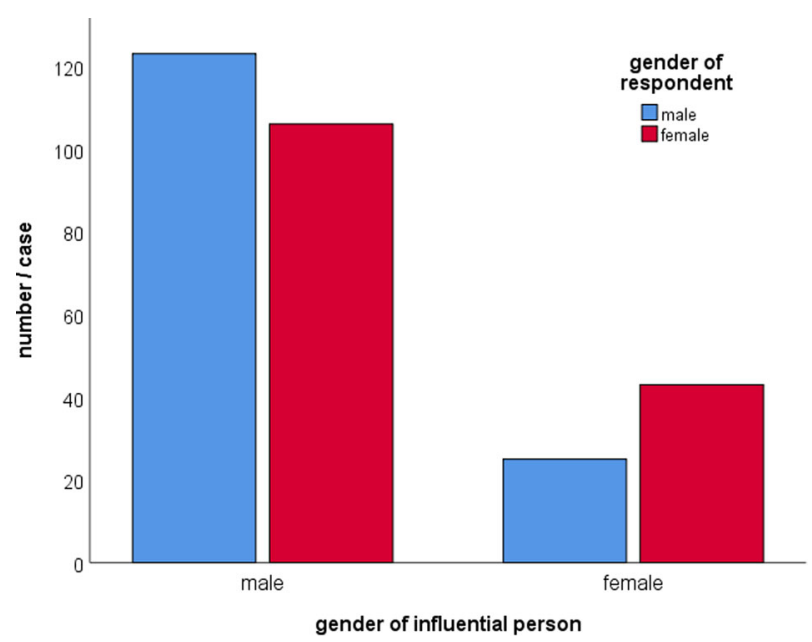

Fig. 2 Gender of respondents and initiators. Relation between own gender and gender of the person most responsible for initial involvement, number of cases according to gender. the family ranks only on place 9 of 10 in men and 7 in women. Concerning McFarlane's study based on Canadian birders (1996), family is on the second place after the category social and before knowledge/opportunity. These differing results might be explained by the survey method. Jones et al. (2017) as well as our study allowed people to decide what they see as their initiation moment, while McFarlane (1996) and Moore et al. (2008) presented Likert-type item, so a participant is forced to answer all questions and weigh them against each other. We consider the open-ended question as better to gain real insight into the initial involvement because it allows participants to respond in detail. They are not forced into a decision.

Our study further allowed to assess the influence of the family members and other persons in more detail compared to previous ones (Jones et al., 2017; McFarlane 1996, Moore et al., 2008). Fathers, and in combination with the mother as parents, made up the majority of initiators. This confirms the importance of the family from previous work (Jones et al., 2017), but in more detail, specifically emphasizing the importance of fathers. Friends only made up $12 \%$. Therefore, the importance for the knowledge transfer seems to be more important within the family cosmos as seen in German pupils and their parents (Remmele and Lindemann-Matthies, 2018). The family influence may be important in comparison to countries, such as Brazil, where the popularization of birdwatching took place during the last decade (Alexandrino et al., 2019; Camargo Barbosa et al., 2021). This is an important venue of future research, because in countries with a long tradition of birding (USA, Sullivan et al., 2014), familial influence is important, while in countries with an emerging birding community, and with different social or cultural context, most birdwatchers probably started birding because of friends, experts, or teachers. This might be also related to the importance of environmental issues (Camargo Barbosa et al., 2021).

Nature experience and experience with birds were other important initiation factors. This stresses the need to allow people visiting nature, and especially to make contact with bird species. This also has implications for park design, i.e., to make bird (or animal) experience possible, also emphasizing the "visibility" of animals/birds, which allows a better nature experience (Randler et al., 2007). Education was further mentioned, both within formal settings (school, university), but also within informal ones, like learning during visits to a nature center. Therefore, it is important to keep biology teaching at school more organism-related to allow contact and experience with birds. The initiation venue via another 


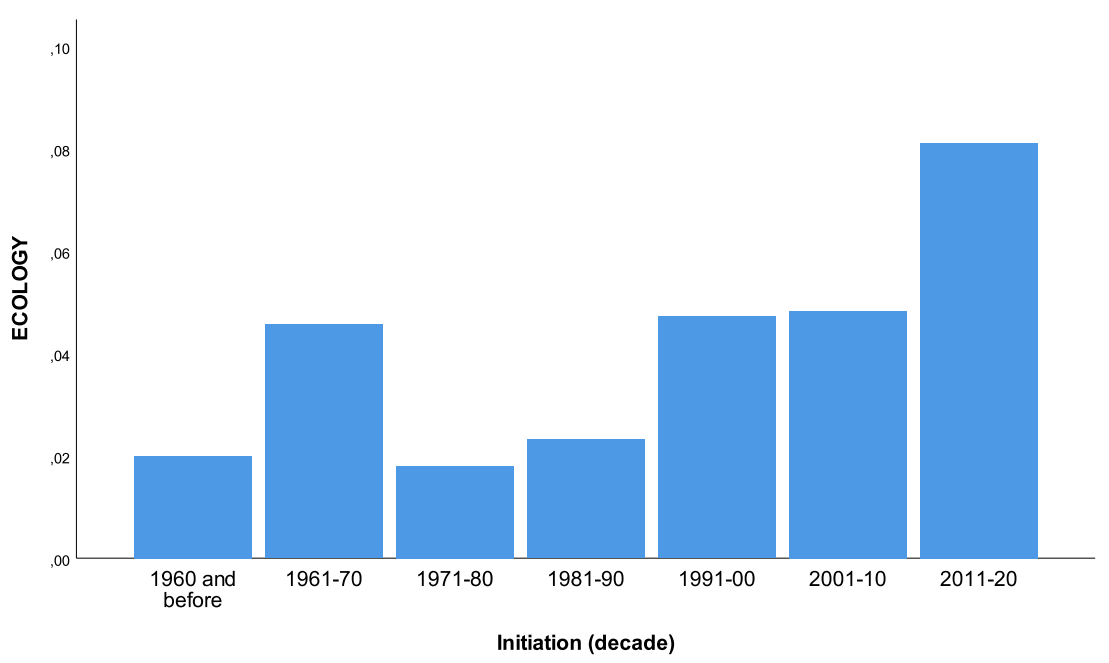

Fig. 3 Effects of decades in relation to initiation. Ecology as reason for initial involvement in relation to decade of initiation.

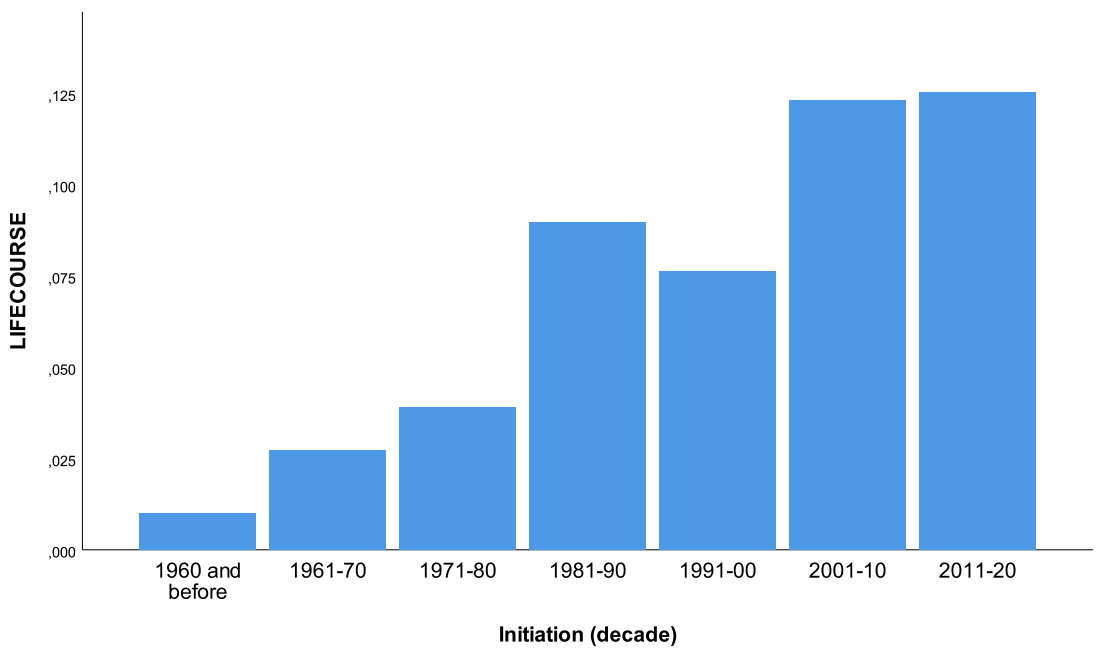

Fig. 4 Effects of decades on the initiation reason life-course event. Life-course events as reason for initial involvement in relation to decade of initiation.

hobby or job is also an interesting aspect because it shows that accident also can lead to a meaningful hobby, even when enforced by a job or civil services.

Citizen science projects and platforms, such as eBird (or ornitho in the local case of Germany, Austria, and Switzerland, respectively), did not seem to have a substantial effect on initiation in this data set. This may have several reasons. First, initiation date may lie before the platforms emerged, given the age and initiation age of our respondents (see also the Figures about the decades of initiation). Second, Randler (2021a, 2021b) suggested that most participants of the German-speaking ornitho citizen science platform usually join the platform when they have already gained a substantial knowledge in bird identification. This may be typical for the German environment and may be different in other countries or samples. For example, in Brazil, Avistar-a Brazilian birdwatching fair in São Paulo city-was the trigger of new birdwatching clubs and of new citizen science initiatives (like WikiAves; Camargo Barbosa et al., 2021). These platforms are the initiation reasons for new Brazilian birdwatchers (Alexandrino et al., 2019). As Brazilian birdwatching emerged mostly during the last decade (Alexandrino et al., 2019; Camargo Barbosa et al., 2021), citizen science platforms significantly foster and boost this movement.

Nevertheless, our study is important with respect to citizen science activities since it shows that other initiations, especially social factors, are important. This leads to the question that citizen science platforms for bird data collection could be improved by people that invite others to become part of this citizen science community, and that, e.g., leaders in birdwatching events (like bird walks) or in nature or ornithological clubs may draw attention towards the different citizen science projects. Our data suggest that the personal instruction and advice may be the most effective way to recruit participants to these platforms.

Gender differences. Significant gender differences were found in some categories: Men experienced birding initiation more by club/ group and the venue other activities (job/hobby). Women were more influenced by nature experience, bird experience, emotions and life-course events. The importance of clubs contrasts with Moore et al. (2008) where women scored higher on this category (e.g., joining a club, taking an organized walk). We can only speculate about this difference, probably it may lie in the different samples (USA versus Germany). Life-course changes seem to be the more relevant trigger in US American women (Moore et al., 2008), with similar results reported by Sali et al. (2008; also an USA-based study). This might be related to gender role stereotypes where women care for the children. Jaumot-Pascual et al. (2016) reported that women tended to be more innovative after retirement and widowhood, while men tended to continue their participation in their life-long leisure activities. Such aspects may also lead to a 


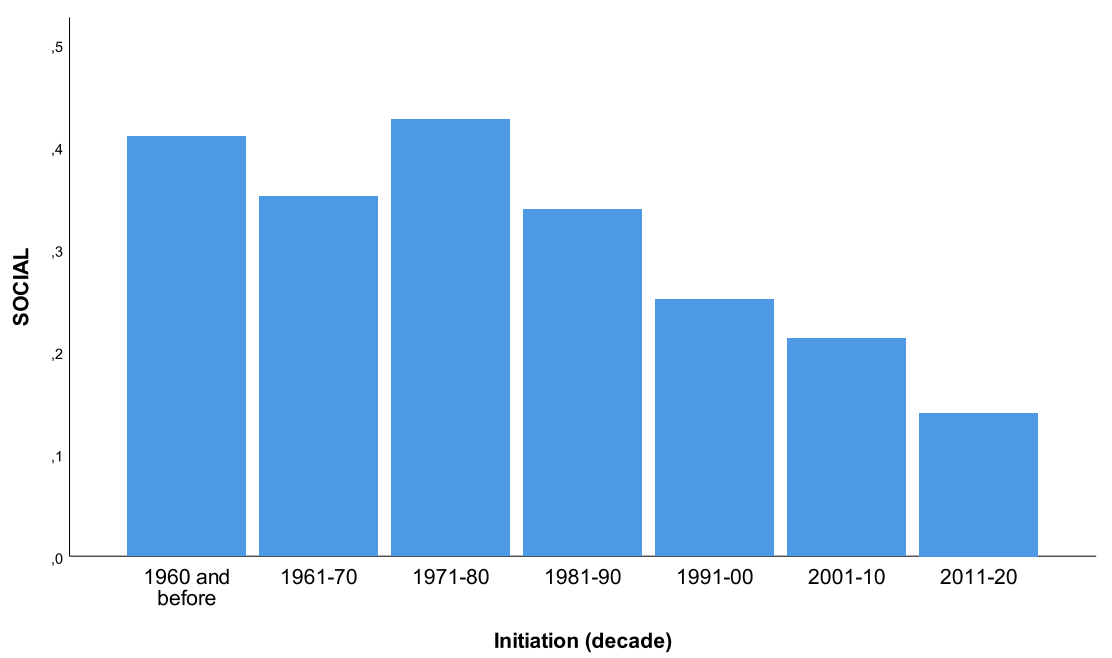

Fig. 5 Effects of decades on social initiation. Social factors as reason for initial involvement in relation to decade of initiation.

higher initiation into birding in women following life-course events. Maintaining a feeder was scored higher in women compared to men (Moore et al., 2008; Sali et al., 2008), which is comparable to our higher bird experience in women. In our categorization, maintaining a feeder is placed within the category experience with birds. Family members were more important in women (Moore et al., 2008), however, in this study we found no differences in the category social, which was mainly made up by the family (Table 2). To sum up, some gender differences seem to be universal across studies (e.g., maintaining a feeder), but others not (like club/group). This deserves further research, probably in other cultures.

Gender differences have been also found in the person responsible for the initial involvement. This is important because it shows that women might be more motivated for birdwatching when another woman serves as a kind of role model or mentor. This is especially important for the development of programs and for nature conservation organization, so that they need to have an eye on an equal share of men and women who may lead field trips (Randler, 2021b).

Leisure career and initiation age. McFarlane (1996) contrasts two venues into birding (and in leisure in general): the childhood model versus the career model. While the childhood model focuses on the initiation during childhood, the career model suggests that initiation into birding happens later in life. Here, we found support for both (see Fig. 1). Thus, some kind of "leisure career" with leisure socialization through the family life cycle in childhood and adolescence was supported (Kelly, 1977). This pattern is corroborated by studies about species knowledge in German children and adolescents where an age of about 9-12 years was identified where the knowledge is highest (Randler, 2008). However, this general pattern could not be replicated here, because many of the initiations occurred outside the family, and also during later years of life, supporting the leisure career model. Statistically, the mean age of initiation (22.9 years) is far away from childhood age. This might be owed to the specialization of birding, which is a different leisure activity, compared to simple activities like sports where initiation can happen easier. Initial involvement in childhood and early adolescence was reported in about $50 \%$ of the people, which seems comparably to our study (Jones et al., 2017). Similarly, in New York birdwatchers, the mean initiation age for males was 22 and of females 23 (Sali et al., 2008). As these ages are quite similar to the ones in our study, it might be a general pattern for birdwatchers.
Decade effects. Decade effects were striking, with a significant decrease in social initiation. This raises the question, whether there is a loss of knowledge within the families, which leads to a decrease in birding interests. Such effects could be encountered by family programs, where children and parents may participate together to strengthen the transmission of knowledge within families. This could be an important topic for program developers, because most programs focus either on a special group (children, retirees) or are unspecific, following the "one suit fits all” dogma. Here, parent-children programs may fill a niche.

Other initiation processes became more important, namely, ecological aspects, life-course events, via another activity and education. Concerning education, this might have filled the gap that the social initiation has left. Similarly, as nature and ecological aspects are becoming increasingly important (especially during the media coverage), this may be responsible for the increasing initiation events.

Life-course events also became more important as initial involvement. This is in contrast to Kuentzel and Heberlein (2008). These authors reported that life-course events decreased the recreation specialization of boaters in a longitudinal survey. In this study, lifecourse events were initiation triggers. However, both studies are not contradictory, because we asked for the initiation experience, while Kuentzel and Heberlein (2008) studied people that already have participated in a leisure activity. In this case, it is most plausible, that life-course events may lead to a decrease in that activity.

\section{Conclusions}

The conclusions for CS projects and nature conservation can be tied together from the results of the current study. Given the findings of initiation age, an early initiation age around 9-12 years is beneficial, because the current results, as well as previous studies on interest and knowledge in animals (Randler, 2008) suggest that during this time frame, an "open window" for these topics exist. As interested birders put more effort in nature conservation (e.g., by engaging in measures in local reserves, or higher donations; McFarlane and Boxall, 1996), a higher engagement in targeting this young population is needed to achieve a better nature conservation when they are adults. Although most initiations happened by parents or family, it is necessary to target children and adolescents at this age group also by non-familial initiators, such as nature conservation associations or by visits of such organizations at school. The results of this study may be transferable to other nature-related activities, such as hiking or mushroom picking, but may be also transferable to other, non-nature-related citizen science activities. 
Implications. The implications are manifold, and may have an impact on teaching, program developers, and nature conservation organizations. For schools as well as informal learning, we suggest more practical work and a focus on natural history-based teaching (Hummel and Randler, 2012) and to foster the experience with living animals, because bird-related experiences were a significant initiation. As mentioned above, parent-children birding programs should be established because there is a similarity between parents and their children in their knowledge and interest (Remmele and LindemannMathies, 2018) and such programs increase the social exchange between both. Another line is the increase of women in leadership in birding because women are important for career success of other women. This postulation can be strengthened by our results.

\section{Data availability}

The data that support the findings of this study are available on request from the author.

Received: 23 July 2021; Accepted: 20 January 2022;

Published online: 08 February 2022

\section{References}

Alexandrino ER, Navarro AB, Paulete VF, Camolesi M, Lima VGR, Green A,... \& do Couto HTZ (2019) Challenges in engaging birdwatchers in bird monitoring in a forest patch: lessons for future citizen science projects in agricultural landscapes. Citiz Sci: Theor Pract 4(1):1-14

Barbosa RDA, Randler C, Robaina JVL (2021) Values and environmental knowledge of student participants of climate strikes: a comparative perspective between Brazil and Germany. Sustainability 13(14):8010

Beck AM, Melson GF, da Costa PL, Liu T (2001) The educational benefits of a ten-week home-based wild bird feeding program for children. Anthrozoös 14(1):19-28

Bjerke T, Kaltenborn BP, Ødegårdstuen TS (2001) Animal-related activities and appreciation of animals among children and adolescents. Anthrozoös 14(2):86-94

Bleidorn W, Klimstra TA, Denissen JJ, Rentfrow PJ, Potter J, Gosling SD (2013) Personality maturation around the world: A cross-cultural examination of social-investment theory. Psychol Sci 24(12):2530-2540

Bonney R (1991) Amateurs welcome. Living Bird 10(1):36-37

Bonney R, Cooper CB, Dickinson J, Kelling S, Phillips T, Rosenberg KV, Shirk J (2009) Citizen science: a developing tool for expanding science knowledge and scientific literacy. BioScience 59(11):977-984

Bonter DN, Greig EI (2021) Over 30 years of standardized bird counts at supplementary feeding stations in north america: a citizen science data report for project feederwatch. Front Ecol Evol 9:170

Camargo Barbosa KV, Develey PF, Ribeiro MC, Jahn AE (2021) The contribution of citizen science to research on migratory and urban birds in Brazil. Ornithol Res 29(1):1-11

Ceccaroni L, Bowser A, Brenton P (2017) Civic education and citizen science: definitions, categories, knowledge representation. In: Analyzing the role of citizen science in modern research. IGI Global. pp. 1-23

Cheung LT, Lo AY, Fok L (2017) Recreational specialization and ecologically responsible behaviour of Chinese birdwatchers in Hong Kong. J Sustain Tour 25(6):817-831

Cooper C, Larson L, Dayer A, Stedman R, Decker D (2015) Are wildlife recreationists conservationists? Linking hunting, birdwatching, and pro-environmental behavior. J Wildlife Manag 79(3):446-457

Genc M, Genc T, Rasgele PG (2018) Effects of nature-based environmental education on the attitudes of 7 th grade students towards the environment and living organisms and affective tendency. Int Res Geogr Environ Educ 27(4):326-340

Gerl T, Randler C, Neuhaus BJ (2021) Vertebrate species knowledge: an important skill is threatened by extinction. Int J Sci Educ 43:928-948

Gläser-Zikuda M, Fuß S, Laukenmann M, Metz K, Randler C (2005) Promoting students' emotions and achievement-Instructional design and evaluation of the ECOLE-approach. Learn Instruct 15(5):481-495

Hopkins GW, Freckleton RP (2002) Declines in the numbers of amateur and professional taxonomists: implications for conservation. Anim Conserv 5(3):245-249

Hummel E, Randler C (2012) Living animals in the classroom: A meta-analysis on learning outcome and a treatment-control study focusing on knowledge and motivation. J Sci Educ Technol 21(1):95-105

Jaumot-Pascual N, Monteagudo MJ, Kleiber DA, Cuenca J (2016) Gender differences in meaningful leisure following major later life events. J Leis Res 48(1):83-103
Jones MG, Corin EN, Andre T, Childers GM, Stevens V (2017) Factors contributing to lifelong science learning: Amateur astronomers and birders. J Res Sci Teach 54(3):412-433

Kelly JR (1974) Socialization toward leisure: A development approach. J Leis Res 6:181-193

Kelly JR (1977) Leisure socialization: Replication and extension. J Leis Res 9:121-132

Kuentzel WF, Heberlein TA (2008) Life course changes and competing leisure interests as obstacles to boating specialization. Leis Sci 30(2):143-157

Kutzner D (2019) Environmental change, resilience, and adaptation in naturebased tourism: Conceptualizing the social-ecological resilience of birdwatching tour operations. J Sustain Tour 27(8):1142-1166

Larson LR, Cooper CB, Futch S, Singh D, Shipley NJ, Dale K, Takekawa JY (2020) The diverse motivations of citizen scientists: Does conservation emphasis grow as volunteer participation progresses? Biol Conserv 242:108428

Mayring P (2001). Combination and integration of qualitative and quantitative analysis. Forum Qual Soc Res. 2:1

Mayring P (2014) Qualitative content analysis: theoretical foundation, basic procedures and software solution. Social Science Open Access Repository, Klagenfurt, Austria

Mayring P (2015) Qualitative Inhaltsanalyse. Grundlagen und Techniken (12., überarbeitete Auflage). Beltz Verlag, Weinheim, Germany

Mayring P (2019) Qualitative content analysis: demarcation, varieties, developments. Forum Qual Soc Res 20:3

McFarlane BL, Boxall PC (1996) Participation in wildlife conservation by birdwatchers. Hum Dimens Wildlife 1(3):1-14

McFarlane BL (1996) Socialization influences of specialization among birdwatchers. Hum Dimens Wildlife 1(1):35-50

McKinley DC, Miller-Rushing AJ, Ballard HL, Bonney R, Brown H, Cook-Patton SC, Ryan SF (2017) Citizen science can improve conservation science, natural resource management, and environmental protection. Biol Conserv 208:15-28

Moore RL, Scott D, Moore A (2008) Gender-based differences in birdwatchers' participation and commitment. Hum Dimens Wildlife 13(2):89-101

Parrish JK, Jones T, Burgess HK, He Y, Fortson L, Cavalier D (2019) Hoping for optimality or designing for inclusion: persistence, learning, and the social network of citizen science. Proc Natl Acad Sci USA 116(6):1894-1901

Pintassilgo P, Pinto P, Costa A, Matias A, Guimarães MH (2021) Environmental attitudes and behaviour of birdwatchers: a missing link. Tour Recreat Res 1-20.

Ploll U, Petritz H, Stern T (2020) A social innovation perspective on dietary transitions: Diffusion of vegetarianism and veganism in Austria. Environ Innov Societ Trans 36:164-176

Randler C, Bogner FX (2007) Pupils' interest before, during, and after a curriculum dealing with ecological topics and its relationship with achievement. Educ Res Eval 13(5):463-478

Randler C, Höllwarth A, Schaal S (2007) Urban park visitors and their knowledge of animal species. Anthrozoös 20(1):65-74

Randler C (2008) Pupils' factual knowledge about vertebrate species. J Baltic Sci Educ 7(1):48-54

Randler C, Wieland L (2010) Knowledge about common vertebrate species in German kindergarten pupils. J Baltic Sci Educ 9:135-141

Randler C (2021a) Users of a citizen science platform for bird data collection differ from other birdwatchers in knowledge and degree of specialization. Global Ecol Conserv 27:e01580

Randler C (2021b) Leaders inspiring the next generation of citizen scientists-an analysis of the predictors of leadership in birding. Front Ecol Evol 9:727719

Randler C, Heil F (2021) Determinants of bird species literacy-activity/interest and specialization are more important than socio-demographic variables. Animals 11(6):1595

Randler C, Staller N, Tryjanowski P (2021) Negative social jetlag-Special consideration of leisure activities and evidence from birdwatchers. J Sleep Res, 30(6): :e13372, 1-8

Remmele M, Lindemann-Matthies P (2018) Like father, like son? On the relationship between parents' and children's familiarity with species and sources of knowledge about plants and animals. EURASIA J Math Sci Technol Educ 14(10):em1581

Sali MJ, Kuehn DM, White D, Grant NS (2008) Birdwatching in New York State: A study of motivations and gender. Hum Dimens Wildlife 13(3):187-200

Sekercioglu CH (2002) Impacts of birdwatching on human and avian communities. Environ Conserv 29(3):282-289

Sullivan BL, Aycrigg JL, Barry JH, Bonney RE, Bruns N, Cooper CB, Kelling S (2014) The eBird enterprise: an integrated approach to development and application of citizen science. Biol Conserv 169:31-40

Trumbull DJ, Bonney R, Bascom D, Cabral A (2000) Thinking scientifically during participation in a citizen-science project. Sci Educ 84(2):265-275

Weston MA, Guay PJ, McLeod EM, Miller KK (2015) Do birdwatchers care about bird disturbance? Anthrozoös 28(2):305-317

White RL, Eberstein K, Scott DM (2018) Birds in the playground: Evaluating the effectiveness of an urban environmental education project in enhancing school children's awareness, knowledge and attitudes towards local wildlife. PLoS ONE 13(3):e0193993 


\section{Acknowledgements}

Naomi Staller established the website for the survey. This study received no additional funding.

\section{Author contributions}

C.R. and N.M. provided substantial contributions to the conception or design of the work; C.R. made the acquisition, N.M. the qualitative analysis, and both authors the interpretation of data for the work; C.R. drafted the first version and both authors agreed on the submission and the final version of the manuscript.

\section{Funding}

Open Access funding enabled and organized by Projekt DEAL.

\section{Competing interests}

The authors declare no competing interests.

\section{Ethical approval}

The research has been performed in accordance with the Declaration of Helsinki and all relevant laws in Germany. The study was granted permission by the Ethics Committee of the Eberhard Karls University Tübingen (Az: A2.5.4-113_aa; Wirtschafts- und Sozialwissenschaftliche Fakultät [faculty for economics and social sciences]).

\section{Informed consent}

Informed consent was obtained from all participants and/or their legal guardians.

\section{Additional information}

Correspondence and requests for materials should be addressed to Christoph Randler.

Reprints and permission information is available at http://www.nature.com/reprints

Publisher's note Springer Nature remains neutral with regard to jurisdictional claims in published maps and institutional affiliations.

(c) (i) Open Access This article is licensed under a Creative Commons Attribution 4.0 International License, which permits use, sharing, adaptation, distribution and reproduction in any medium or format, as long as you give appropriate credit to the original author(s) and the source, provide a link to the Creative Commons license, and indicate if changes were made. The images or other third party material in this article are included in the article's Creative Commons license, unless indicated otherwise in a credit line to the material. If material is not included in the article's Creative Commons license and your intended use is not permitted by statutory regulation or exceeds the permitted use, you will need to obtain permission directly from the copyright holder. To view a copy of this license, visit http://creativecommons.org/ licenses/by/4.0/.

(C) The Author(s) 2022 